\title{
Synthesis, Characterization and Luminescence Properties
}

\section{of a New Series of $\mathrm{Eu}^{3+}$ - Containing Macrocycles}

\author{
Christopher G. Gulgas and Theresa M. Reineke* \\ Department of Chemistry, University of Cincinnati, Cincinnati, OH 45221-0172
}

AUTHOR EMAIL ADDRESS:Theresa.Reineke@uc.edu

Supporting Information

Table of Contents

1. ESI-MS of 3

2. ESI-MS of 4

3. ESI-MS of 5

4. ESI-MS of 6

5. ESI-MS of 7

6. ESI-MS of $\mathbf{E u ( 4 )}$

7. ESI-MS of $\mathbf{E u ( 5 )}$

8. ESI-MS of $\mathbf{E u ( 6 )}$

9. ESI-MS of $\mathbf{E u ( 7 )}$

10. ESI-MS-MS of 7

11. ${ }^{1} \mathrm{H}-\mathrm{NMR}$ spectra of 4-7

12. Absorption Spectra of $\mathbf{E u ( 4 ) - E u ( 7 ) ~}$

13. Excitation Spectra of $\mathbf{E u ( 4 ) - E u ( 7 )}$

14. Emission Spectra of $\mathbf{E u ( 4 ) - E u ( 7 )}$ 
1. ESI-MS of 3

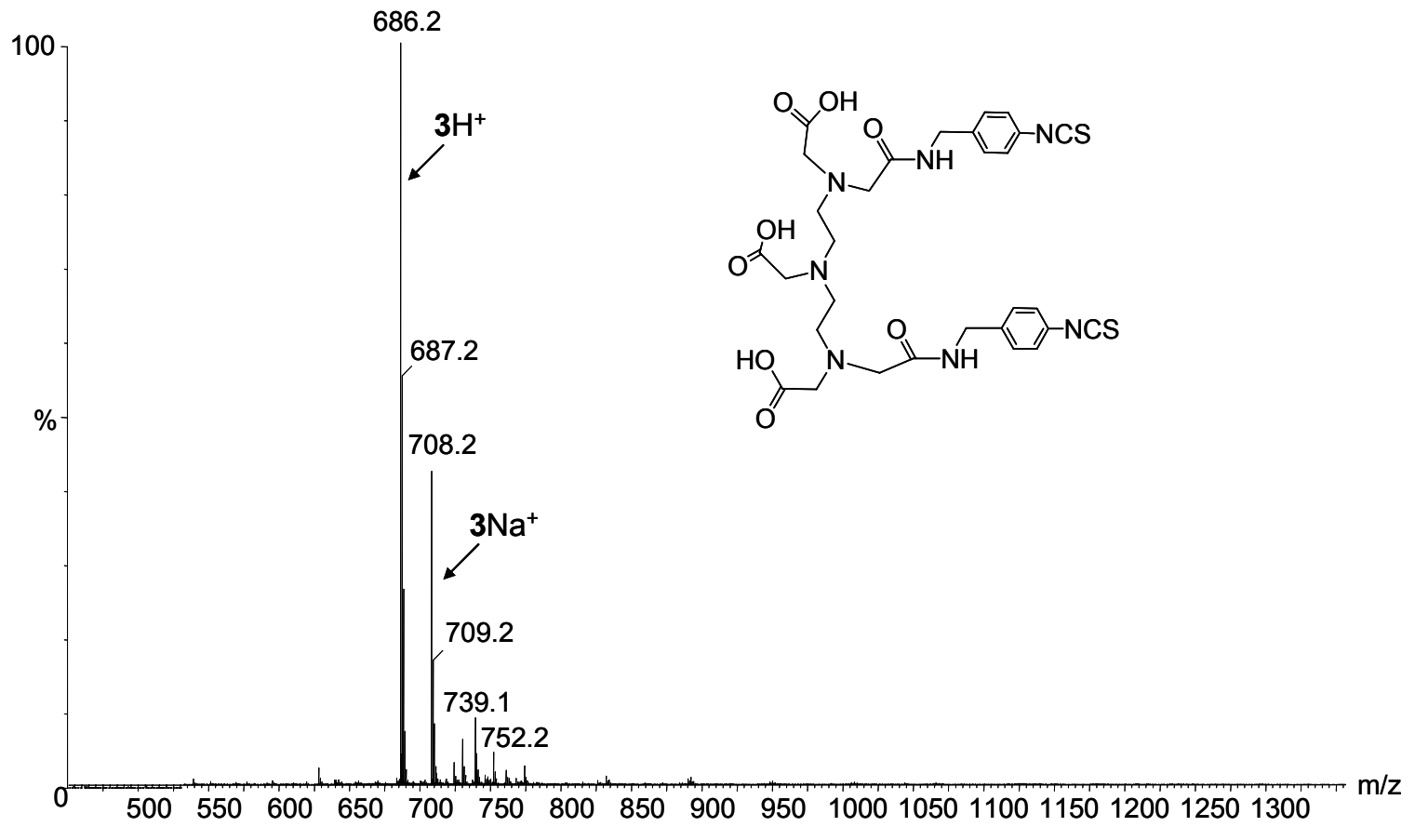




\section{ESI-MS of 4}

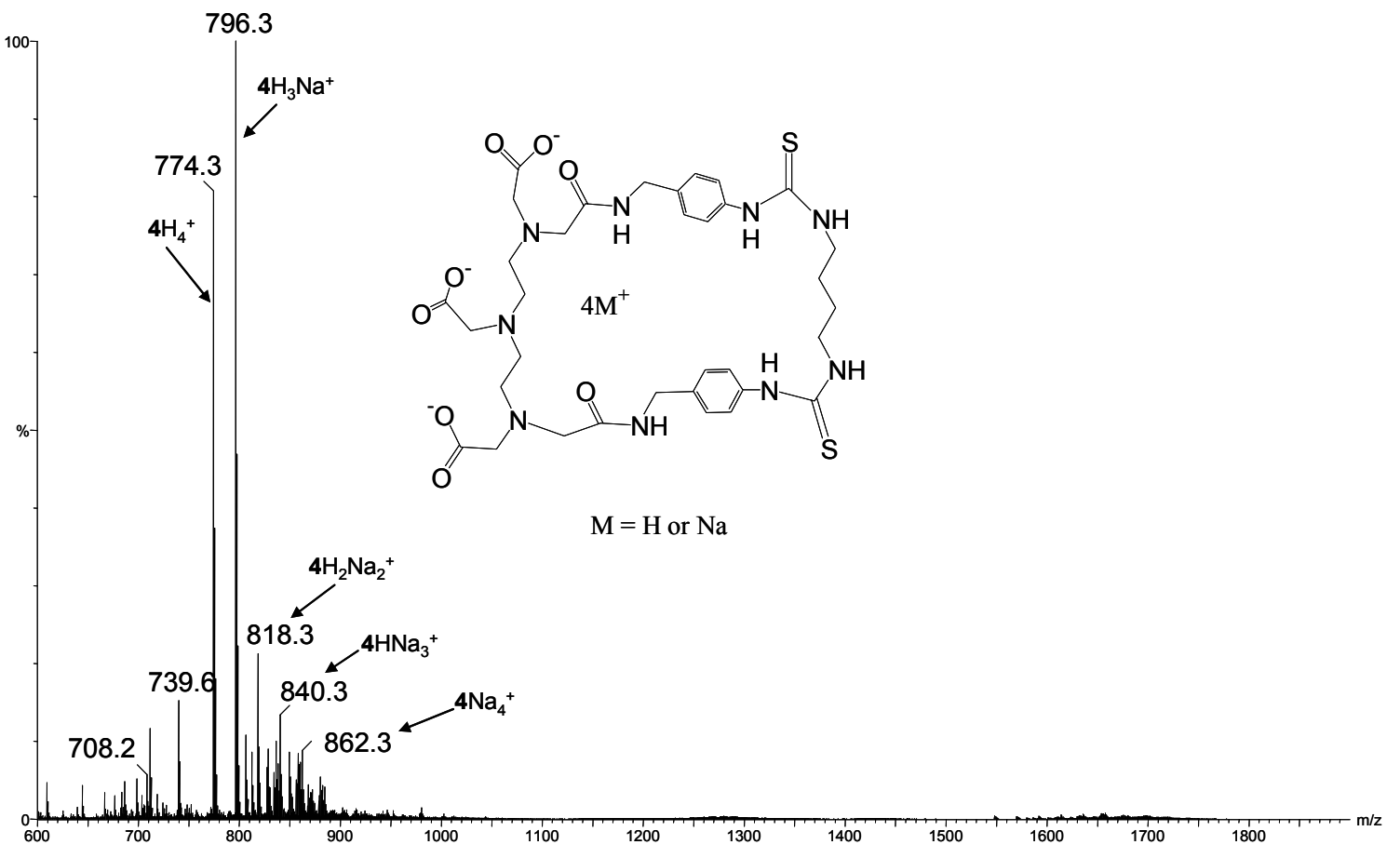




\section{ESI-MS of 5}

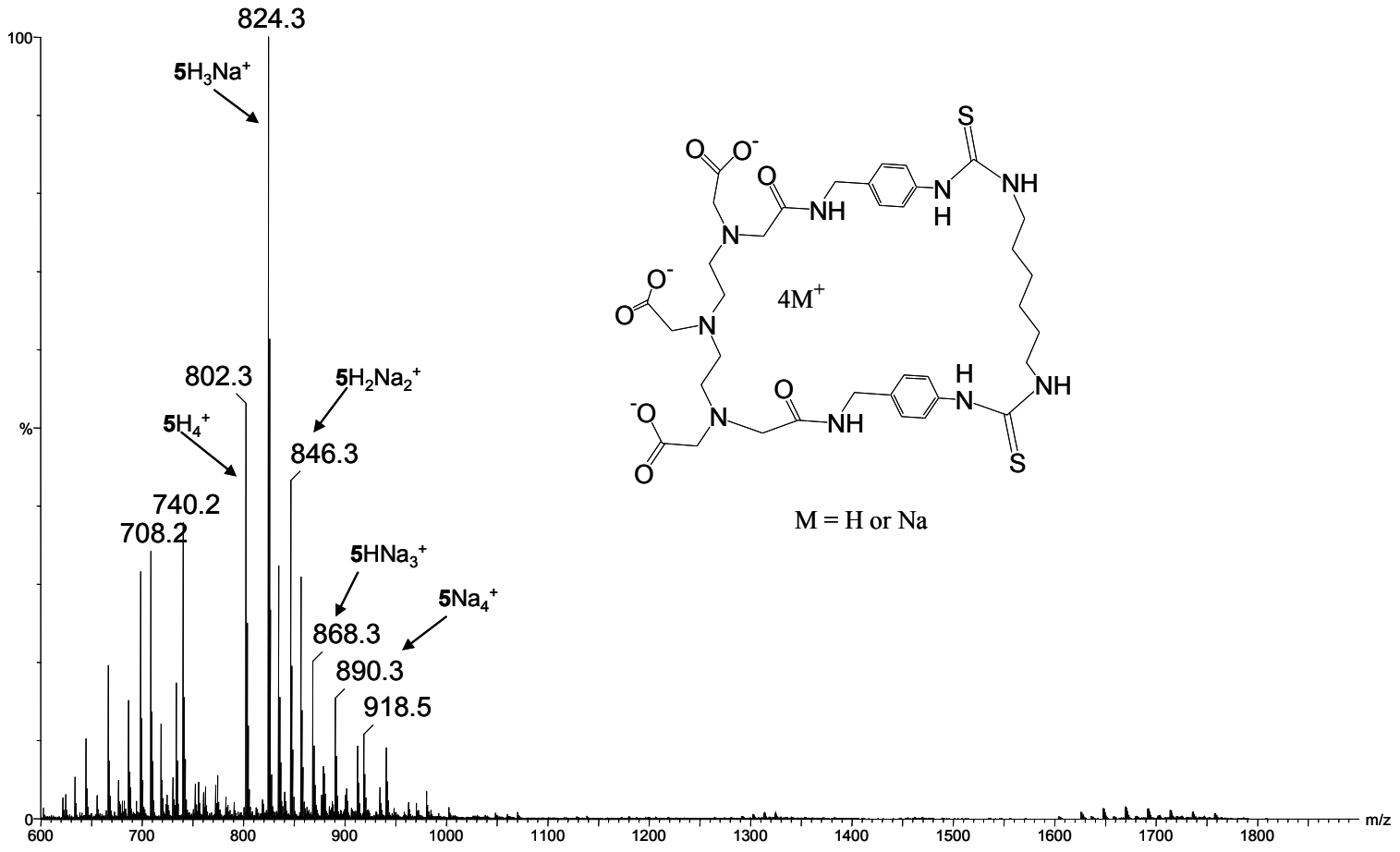




\section{ESI-MS of 6}

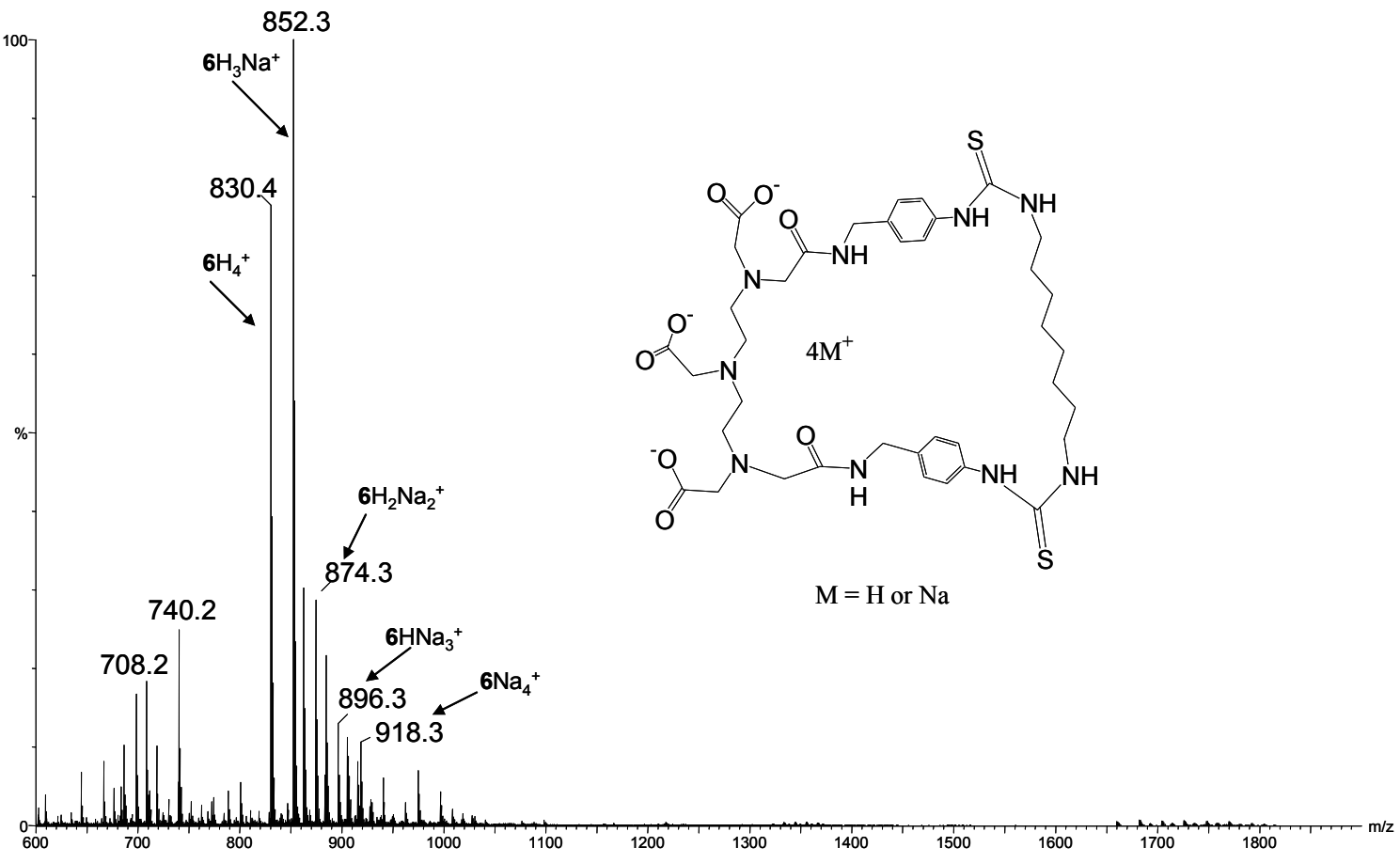




\section{ESI-MS of 7}

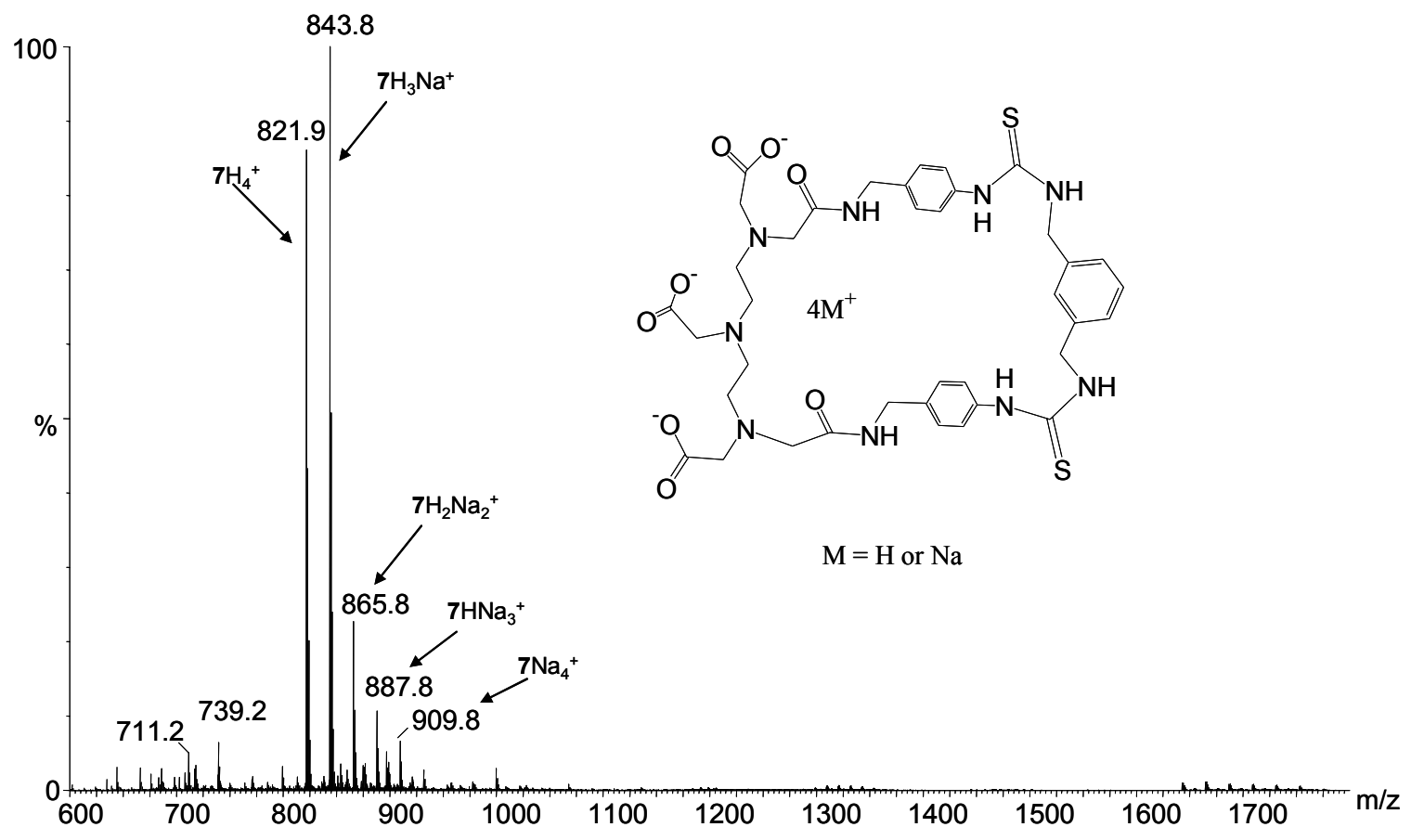




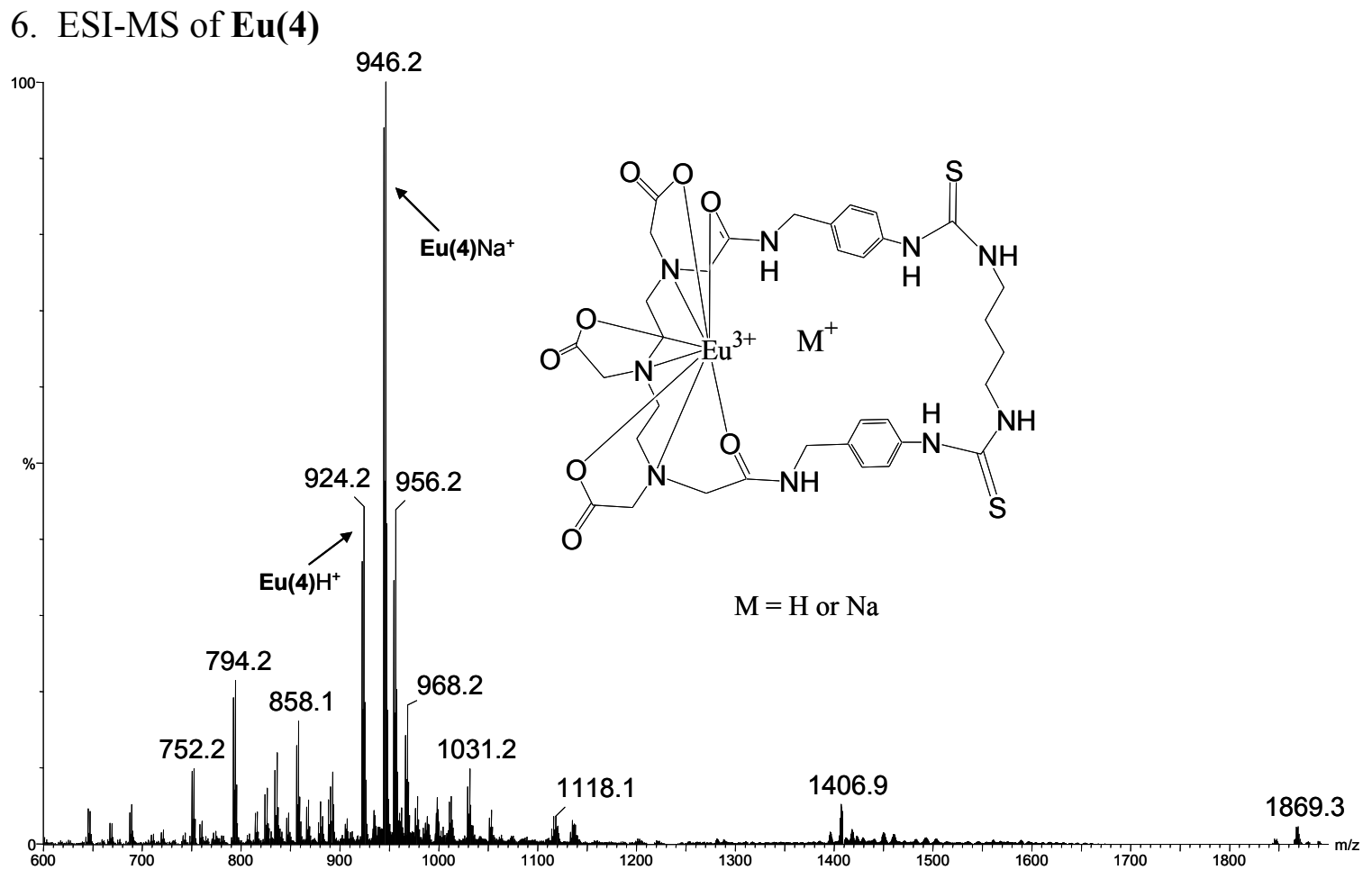


7. ESI-MS of $\mathbf{E u ( 5 )}$

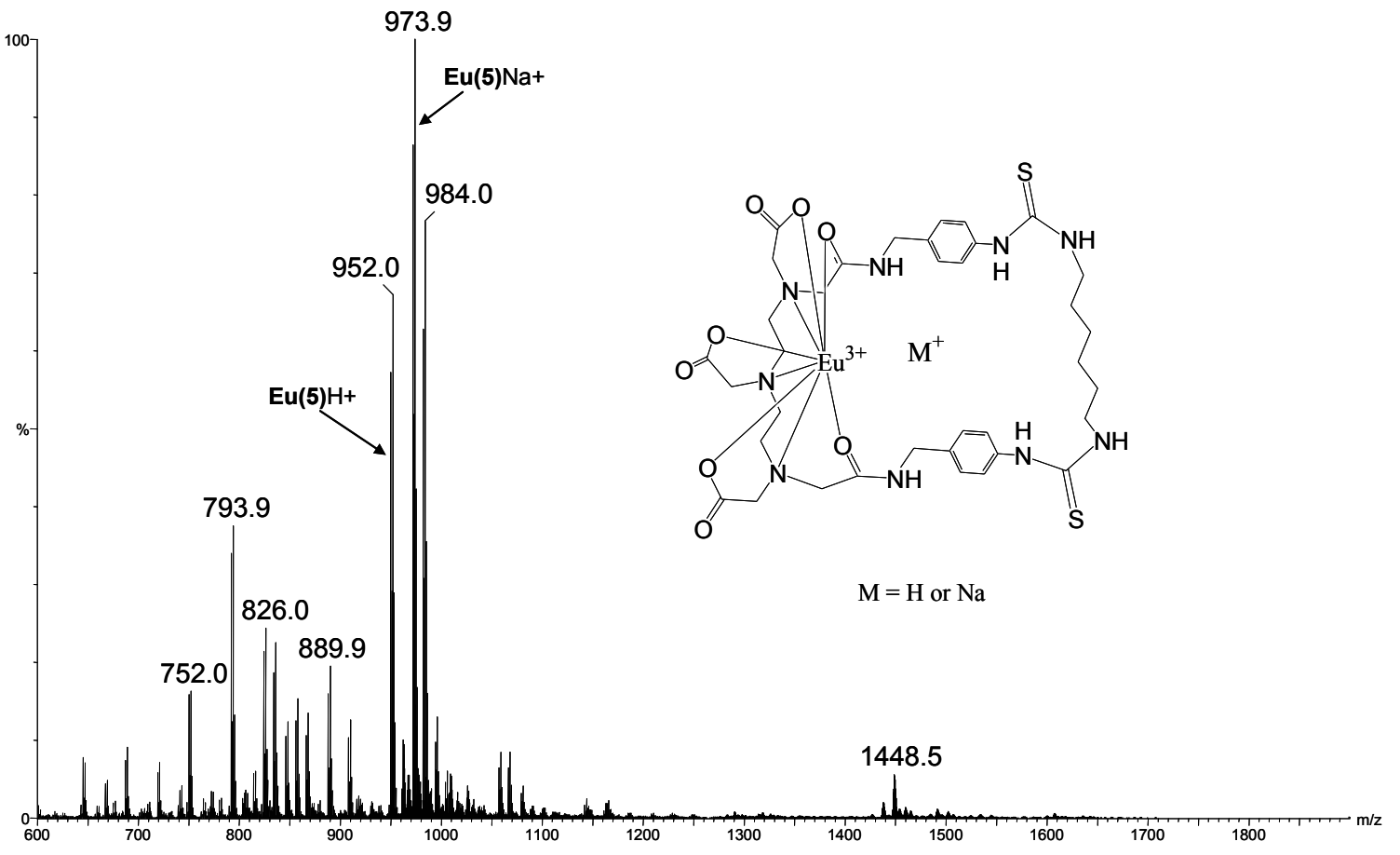




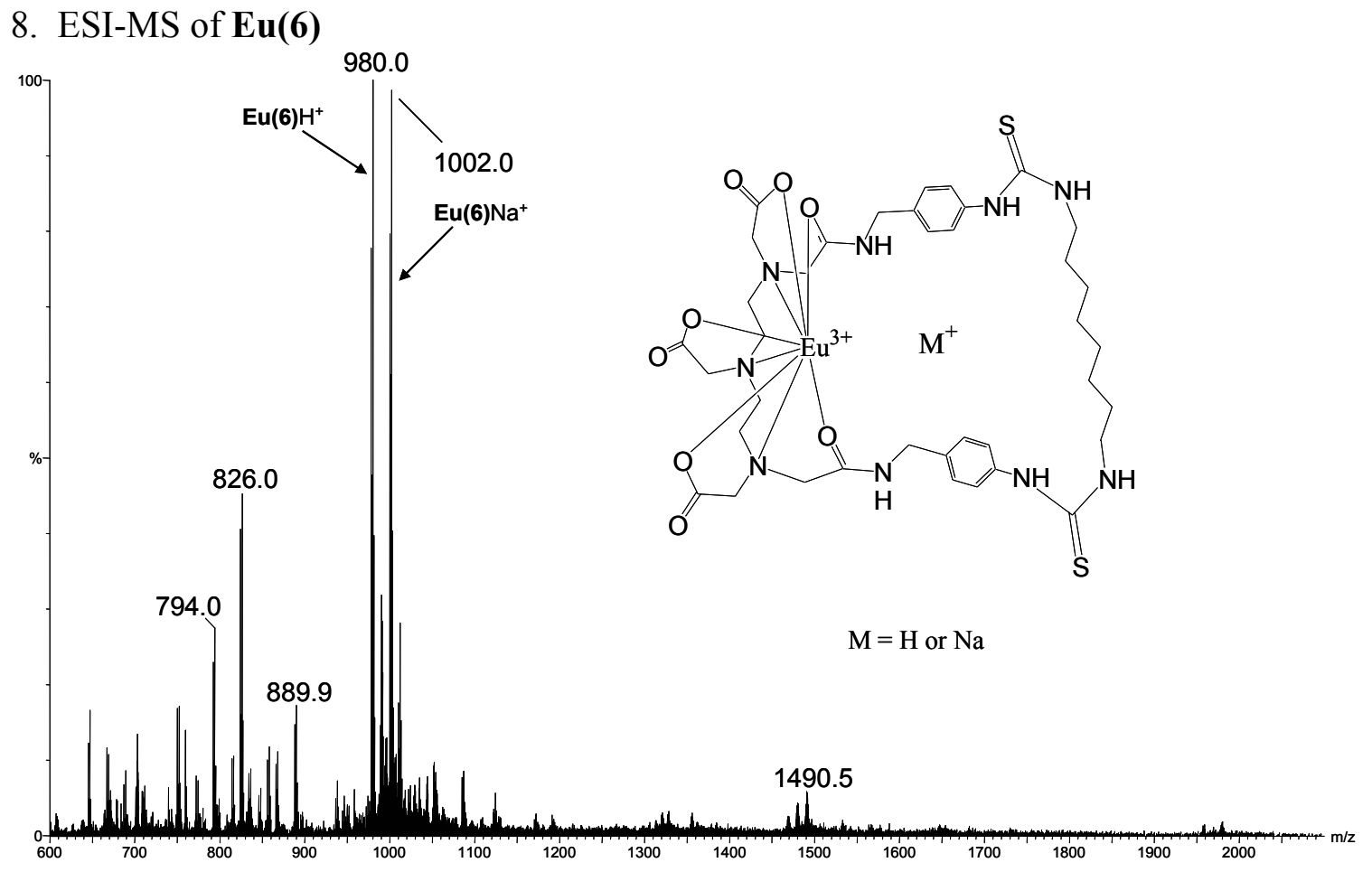




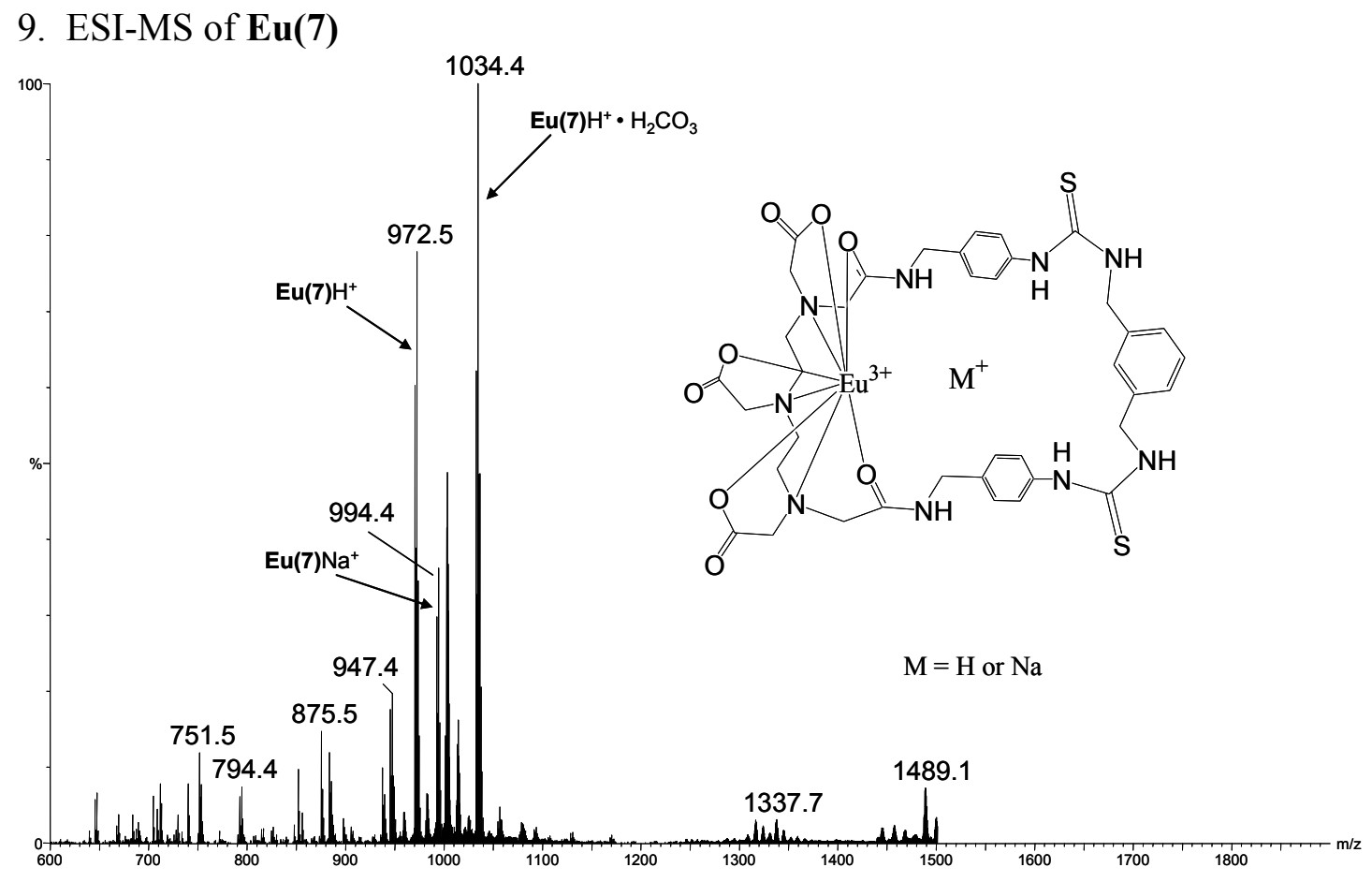


10. ESI-MS-MS of 6. (a) ESI-MS of 6 from 1600-1880 m/z. (b) MS of the 1660.7 $\mathrm{m} / \mathrm{z}$ species at $6 \mathrm{eV}$ (c) MS of the $1660.7 \mathrm{~m} / \mathrm{z}$ species at $15 \mathrm{eV}$ (d) MS of the $1660.7 \mathrm{~m} / \mathrm{z}$ species at $45 \mathrm{eV}$ (e) MS of the $1660.7 \mathrm{~m} / \mathrm{z}$ species at $65 \mathrm{eV}$
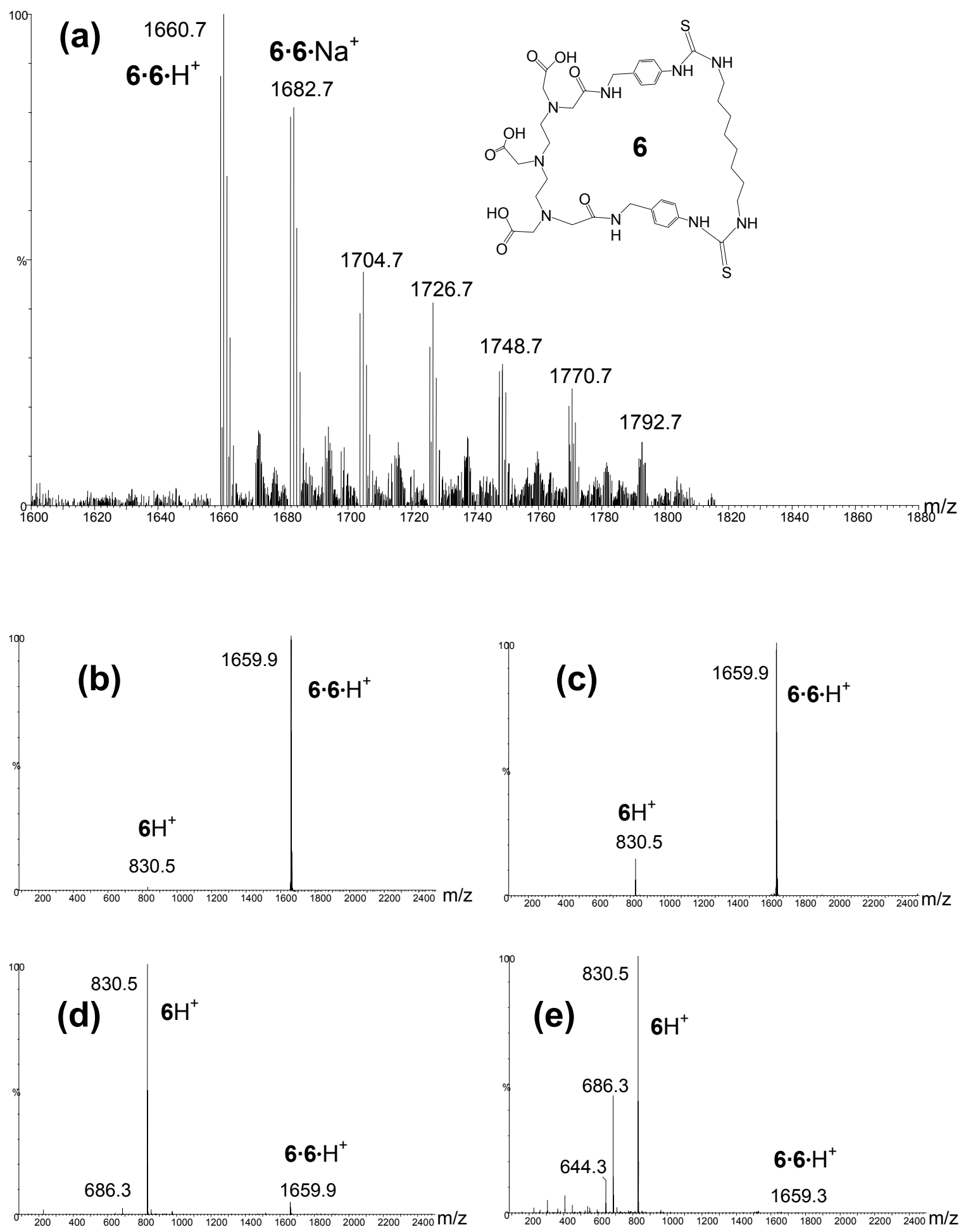
11. ${ }^{1} \mathrm{H}-\mathrm{NMR}$ spectra of 4-7 $\left(\mathrm{D}_{2} \mathrm{O}, \mathrm{pH} \approx 10\right)$. Solvent contamination arises from $\mathrm{MeOH}$ (3.35 ppm) and DMF (2.88 and $3.05 \mathrm{ppm}$ ). Resonances due to TMS standard occur at 0.8 and $2.2 \mathrm{ppm}$.

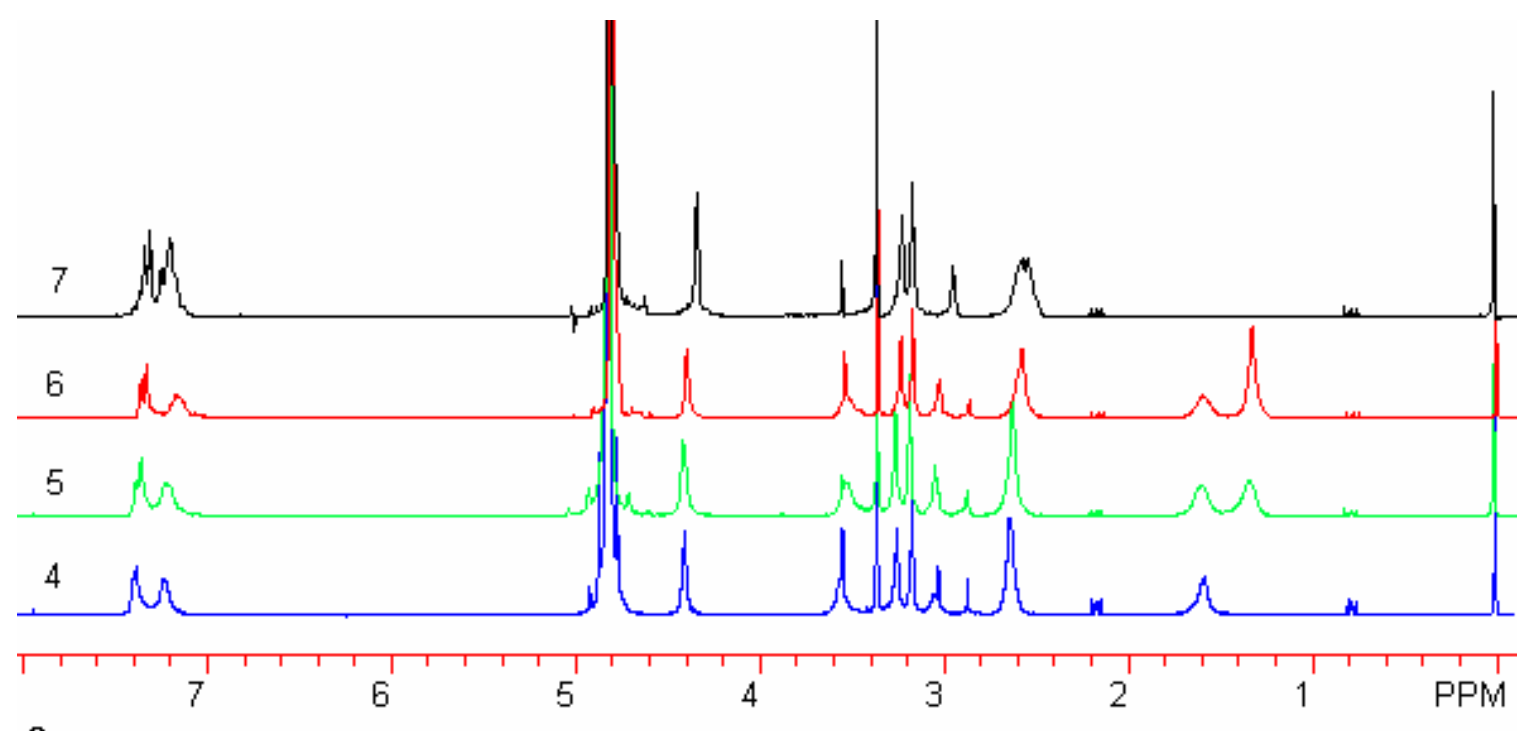


12. Absorption Spectra of $\mathbf{E u ( 4 ) - E u ( 7 ) ~ i n ~} \operatorname{DMSO}\left(1.00 \times 10^{-5} \mathrm{M}\right)$. (a) $\mathbf{E u ( 4 ) ~ ( b ) ~}$ $\operatorname{Eu}(5)$ (c) $\operatorname{Eu}(6)$ (d) $\operatorname{Eu}(7)$

a

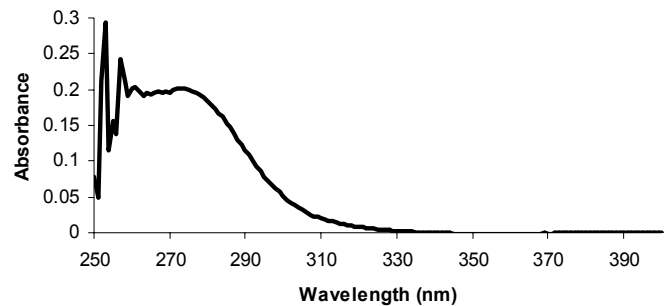

c

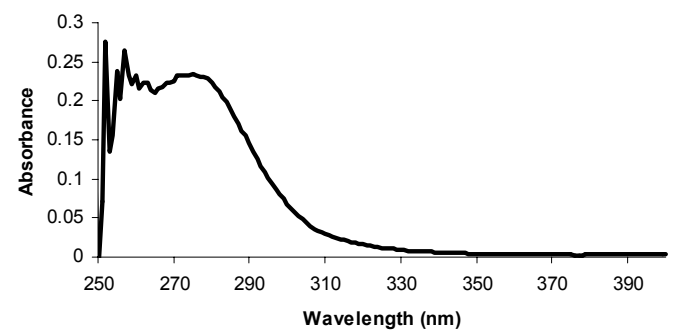

b

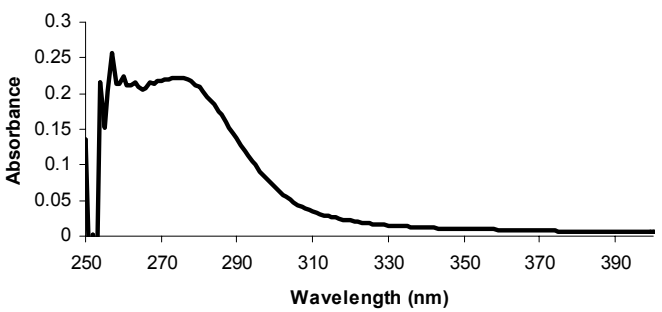

d

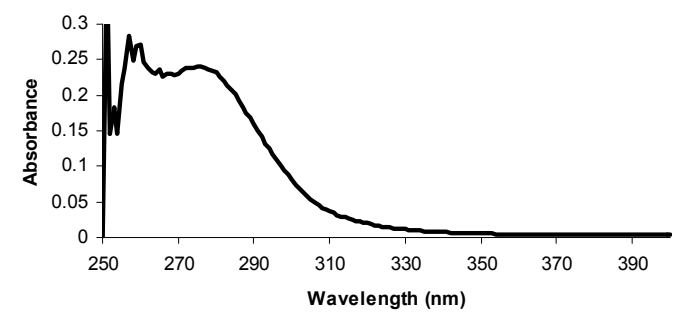


13. Excitation Spectra of $\mathbf{E u ( 4 ) - E u ( 7 ) ~ i n ~} \operatorname{DMSO}\left(2.0 \times 10^{-5}\right.$ M). (a) $\mathbf{E u ( 4 ) ~ ( b ) ~} \mathbf{E u ( 5 )}$ (c) $\mathbf{E u}(6)$ (d) $\mathbf{E u}(7)$

a

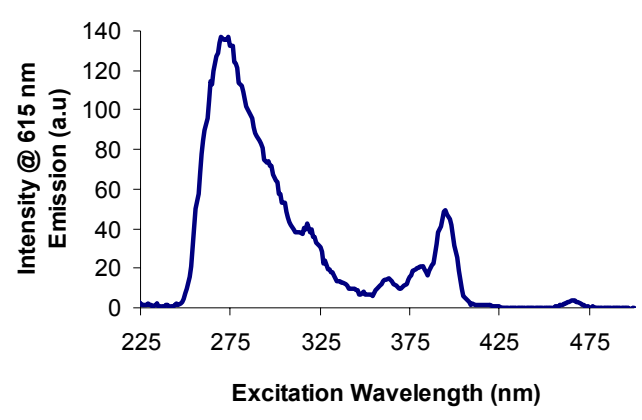

c

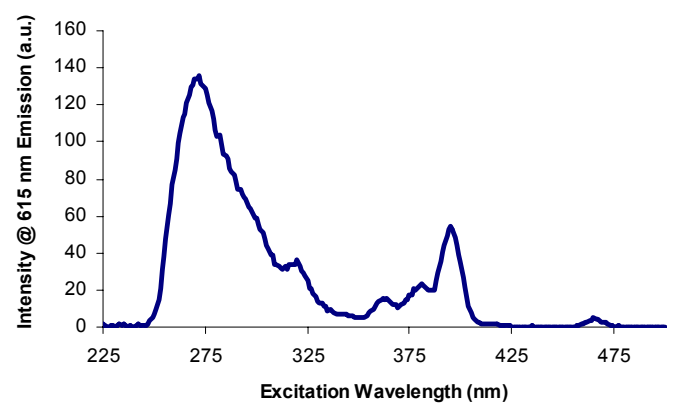

b

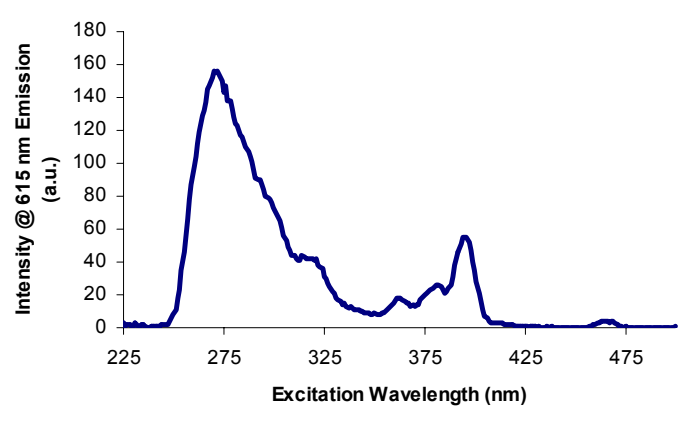

d

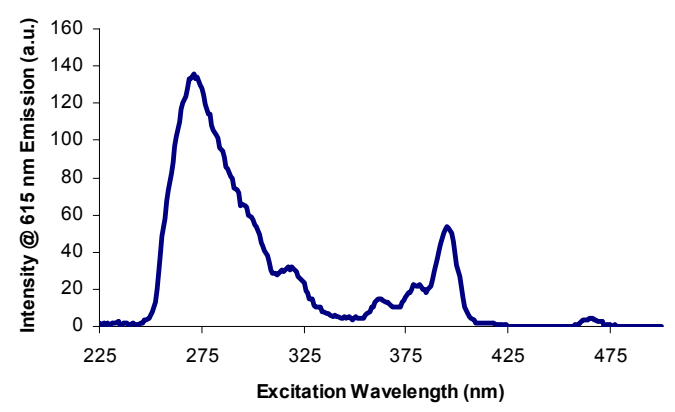


14. Emission Spectra of $\mathbf{E u}(4)-\mathbf{E u}(7)$ in $\operatorname{DMSO}\left(2.0 \times 10^{-5} \mathrm{M}\right)$. (a) $\mathbf{E u ( 4 ) ~ ( b ) ~} \mathbf{E u ( 5 )}$ (c) $\operatorname{Eu}(6)(d) \operatorname{Eu}(7)$

a

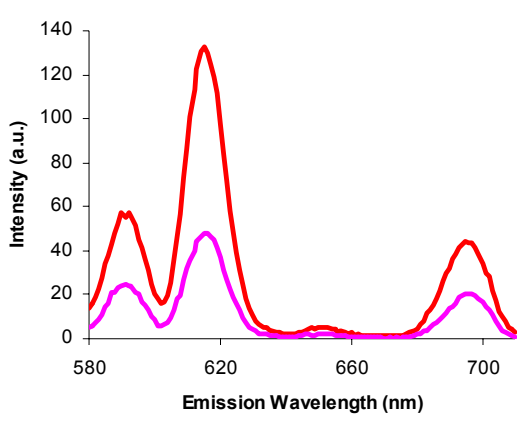

C

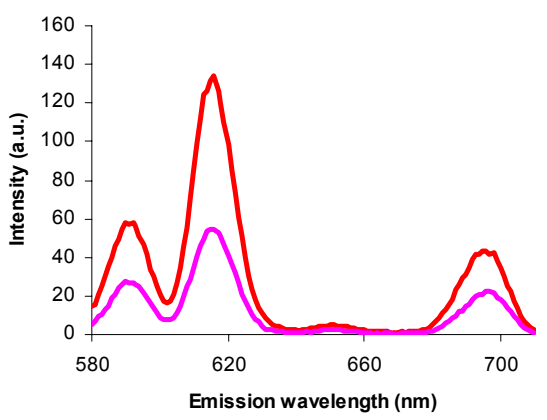

b

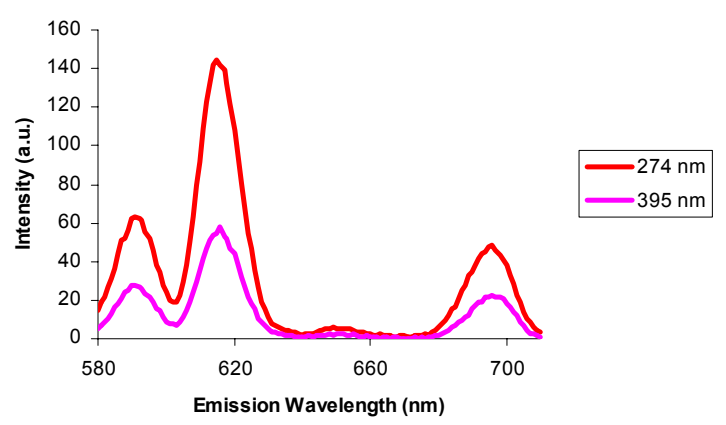

d

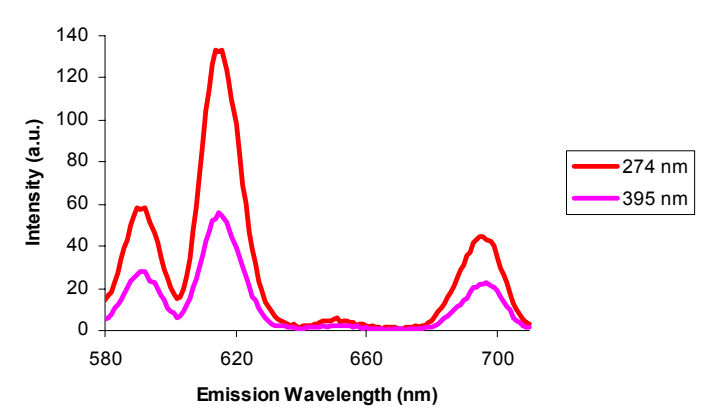

